\title{
The Annual Trip to the Ice-rink: A Seasonal Cause of Wrist Trauma in Irish Hospitals
}

\author{
Martin Davey ${ }^{1}$, Matt Davey ${ }^{2}$, Marc C. Grant-Freemantle ${ }^{3}$, Sean Flynn ${ }^{3}$, Gavin McHugh ${ }^{3}$ \\ 1. Trauma and Orthopaedics, Royal College of Surgeons, Dublin, IRL 2. Plastic, Aesthetic, and Reconstructive Surgery, \\ Galway University Hospitals, Galway, IRL 3. Trauma and Orthopaedics, Beaumont Hospital, Dublin, IRL
}

Corresponding author: Matt Davey, m.davey7@nuigalway.ie

\begin{abstract}
Fractures of the distal radius are a common orthopaedic presentation in Irish emergency departments. As a nation, Irish people tend to ice-skate seasonally with a peak of interest seen during the Winter months in temporary ice-rinks. This case series describes winter ice-skating as a significant cause of wrist fractures in the younger patient, including five cases of distal radius fractures, four of which ultimately required internal fixation, under general anaesthesia, over a single weekend in the month of December. Despite all five patients being amateur ice-skaters, all denied ever having taken ice-skating lessons. This demonstrates the dangers of wrist trauma in the inexperienced or beginner ice-skaters on temporary ice-rinks; the seasonal morbidity suffered as a result.
\end{abstract}

Categories: Orthopedics, Public Health, Trauma

Keywords: trauma, orthopaedics, ice, skating, ireland, wrist, fracture

\section{Introduction}

Fractures of the distal radius are common presentations in the western world, accounting for over $16 \%$ of orthopaedic trauma presentations in emergency departments [1]. Nearly two-thirds of all distal radius fractures are reported to occur following low-velocity trauma in the elderly, osteoporotic patient. Such wrist fractures are reported to correlate with significant morbidity [2]. However, in younger patients, sporting injuries are reported to the leading cause of distal radius fractures [3].

Due to Ireland's cool temperate oceanic climate, participation in ice-skating is typically only facilitated using non-natural ice-skating rinks. Therefore, peaks of interest in ice-skating are seen in Ireland during the Christmas period with seasonal ranks opening on a temporary basis in December nationwide. Despite the significant morbidity associated with this activity, many amateur Irish ice-skaters elect to ice-skate without having undergone lessons leading to a significant increase in ice-skating related injuries presenting to Irish emergency departments [4]. This case series demonstrates the dangers of wrist trauma associated with seasonal ice-skating and the morbidity suffered as a result.

Received 01/16/2020

Review began 01/19/2020 Review ended 01/19/2020 Published 01/23/2020

(c) Copyright 2020

Davey et al. This is an open access article distributed under the terms of the Creative Commons Attribution License CC-BY 3.0., which permits unrestricted use, distribution, and reproduction in any medium, provided the original author and source are credited.

\section{Case Presentation}

\section{Case 1}

A 40-year-old right-hand-dominant lady presented to the emergency department following a fall on an outstretched hand (FOOSH) injury whilst ice-skating. She suffered an extra-articular distal radius fracture with dorsal comminution and angulation to her non-dominant left hand (Figure 1). Following the reduction in the emergency department, she was treated with open reduction and internal fixation using a Variable Angle LCP Two-Column Volar Distal Radius Plate 2.4 (DePuy Synthes Comp, IND, USA) (Figure 2). 


\section{Cureus}

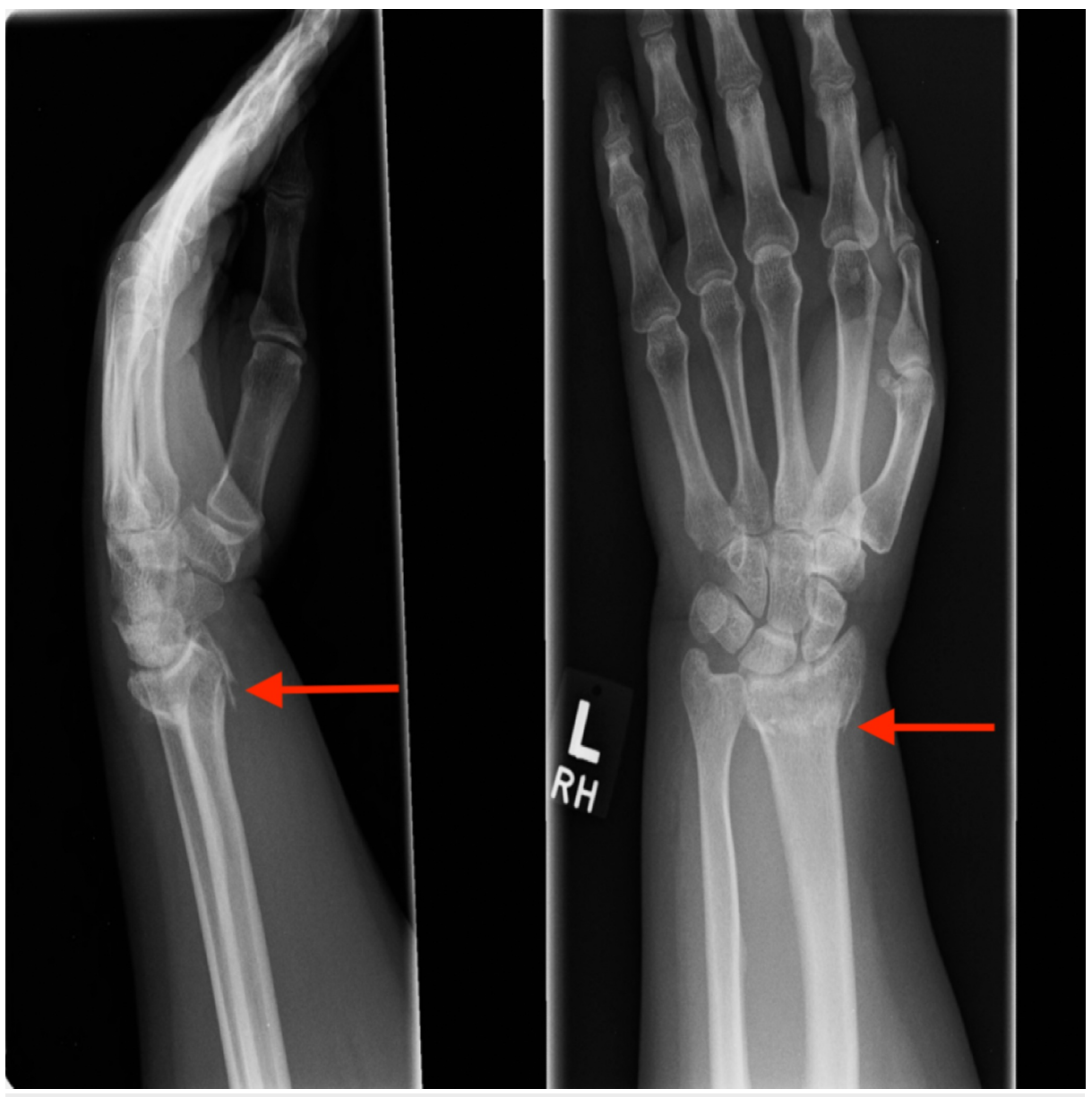

FIGURE 1: Extra-articular distal radius fracture discussed in Case 1 


\section{Cureus}

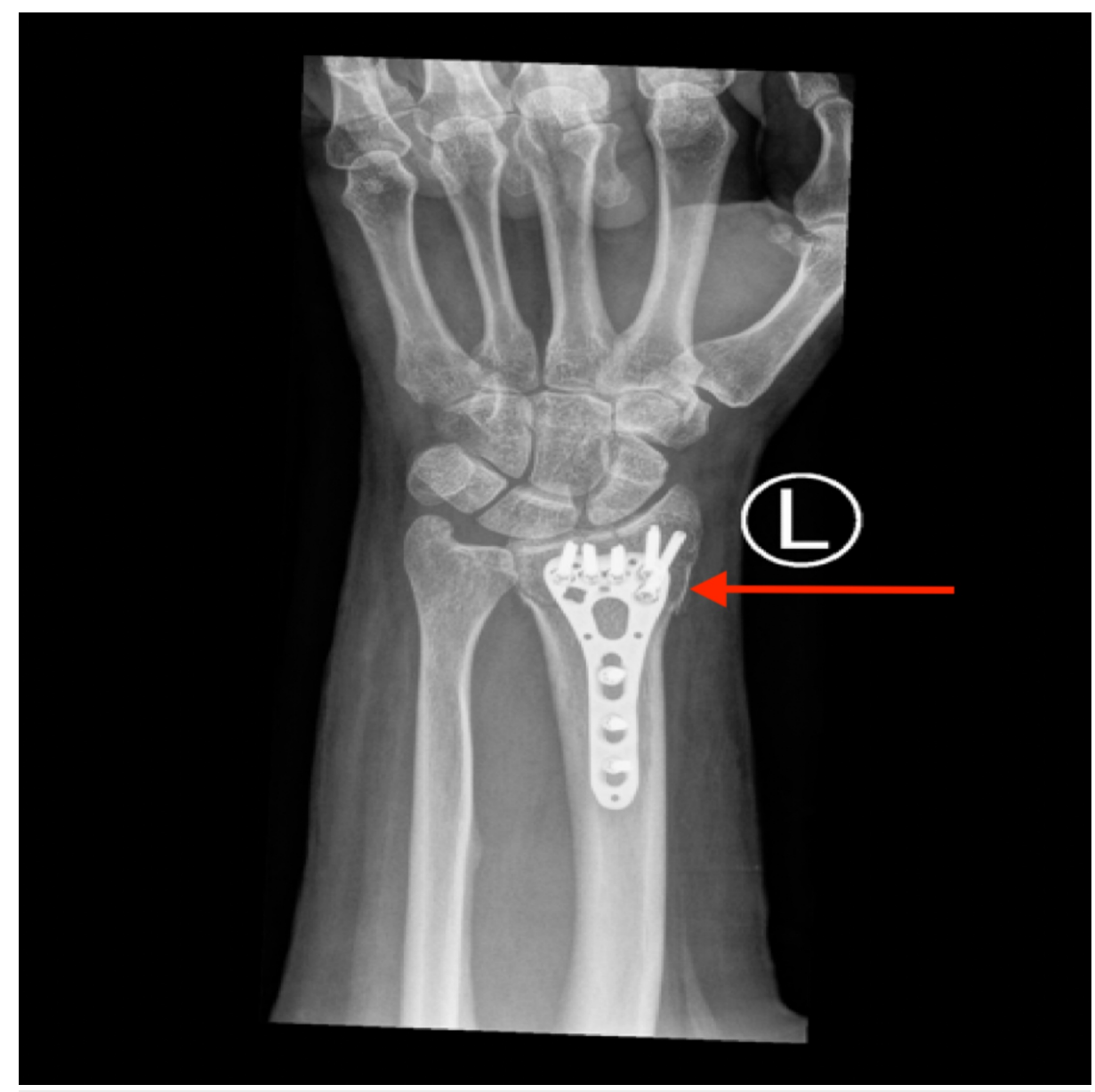

FIGURE 2: Open reduction and internal fixture of the distal radius fracture, of the patient discussed in Case 1, using a Variable Angle LCP Two-column Volar Distal Radius Plate

LCP: Locking compression plate.

\section{Case 2}

A 53-year-old right-hand-dominant lady presented to the emergency department following a fall backwards whilst holding hands with her friend while ice-skating. She suffered an extra-articular distal radius fracture with dorsal comminution and angulation to her dominant right hand; this had been the contra-lateral hand to that held whilst ice-skating. Following the reduction in the emergency department, she was treated with open reduction and internal fixation using an Angle Stable Distal Radial Plate System (Marquardt Group, Rietheim-Weilheim, Germany).

\section{Case 3}

A 36-year-old left-hand-dominant female teacher presented to the emergency department following a fall during her first-time ice-skating. She suffered an intra-articular distal radius fracture with dorsal angulation and severe comminution to her dominant left hand. She underwent open reduction and internal fixation using a Variable Angle LCP Two-Column Volar Distal Radius Plate 2.4; she remained off work during the holidays.

\section{Case 4}

A 41-year-old right-hand-dominant lady presented to the emergency department after a FOOSH injury whilst ice-skating. She suffered an intra-articular left distal radius fracture involving a significant portion of the radial styloid. She underwent closed reduction using two $1.6 \mathrm{~mm}$ Krischner wires (k-wires). She was neurovascularly intact post-operatively. Her k-wires were removed in the outpatient department at sixweeks with satisfactory fixation.

\section{Case 5}


A 37-year-old right-hand-dominant lady presented to the emergency department after falling backwards onto an out-stretched left hand whilst ice-skating. This resulted in an extra-articular left distal radius fracture with dorsal comminution. She was neurovascularly intact. This lady was treated conservatively using a molded cast and followed up in the outpatient fracture clinic thereafter.

\section{Discussion}

Distal radius fractures are reported to occur more commonly in elderly, osteoporotic patients [4]. Our case series discusses the intermittent, annual trips to an ice-skating rink as a significant cause of morbidity for the young, active patient. As all five distal radius fractures presented over one weekend in December; this sparked curiosity for the authors. Ice-skating is a seasonal leisure activity in Ireland that accounts for significant trauma, particularly in the month of December [4].

As a nation, ice-skating remains a novelty to the Irish population, which is commonly enjoyed during the Christmas period [4]. Ice-skating injuries, although serious in nature, are thought to represent less than $1 \%$ of emergency department referrals during this time period [5]. Due to the sporadic nature of our engagement with the activity, few people elect to receive full ice-skating lessons prior to skating in a full-sized ice-rink [6]. Williamson et al. postulated that of those who sustain injuries whilst ice-skating, $75 \%$ will be beginners and $92 \%$ will never have received formal tuition or lessons [7]. Similarly, Matsumoto et al. reported that of those who suffer distal radius fractures during winter sporting and leisure activities, nearly $95 \%$ will never have had formal professional instruction [8].

Significant trauma can occur as a result of ice-skating and serious injuries (including distal radius fractures) related to this activity tend to occur in beginner ice-skaters [9]. Despite the majority of ice-skating injuries occurring in inexperienced or beginner ice-skating, over $40 \%$ of advanced ice-skaters will suffer a severe injury on the ice during their lifetime [10]. Of the trauma which occurs, it has been shown that upper limb trauma remains the commonest injury presenting to emergency departments following ice-skating accidents, with studies reporting that distal radius fractures may account for $45 \%-82 \%$ of such presentations $[4,11]$.

\section{Conclusions}

This case series demonstrates the risk distal radius fractures in light of our desire to enjoy the hazardous activity of ice-skating on the annual trip to the temporary ice-rink. Furthermore, acknowledgement must be given to the fact that ice-skating lessons may need to be more widely available to newcomers and amateur ice-skaters. This, alongside significant public education, may play a role in the future to reduce the burden on our emergency departments.

\section{Additional Information \\ Disclosures}

Human subjects: Consent was obtained by all participants in this study. Conflicts of interest: In compliance with the ICMJE uniform disclosure form, all authors declare the following: Payment/services info: All authors have declared that no financial support was received from any organization for the submitted work. Financial relationships: All authors have declared that they have no financial relationships at present or within the previous three years with any organizations that might have an interest in the submitted work. Other relationships: All authors have declared that there are no other relationships or activities that could appear to have influenced the submitted work.

\section{References}

1. Chung KC, Spilson SV: The frequency and epidemiology of hand and forearm fractures in the United States . J Hand Surg. 2001, 26:908-915. 10.1053/jhsu.2001.26322

2. Niempoog S, Sukkarnkosol S, Boontanapibul K: Prevalence of osteoporosis in patients with distal radius fracture from low-energy trauma. Malays Orthop J. 2019, 13:15-20. 10.5704/MOJ.1911.003

3. Lawson GM, Hajducka C, McQueen MM: Sports fractures of the distal radius - epidemiology and outcome . Injury. 1995, 26:33-36. 10.1016/0020-1383(95)90549-d

4. Clarke HJ, Ryan D, Cusack S: The impact of a temporary ice-rink on an emergency department service . Eur J Emerg Med. 2006, 13:204-208. 10.1097/01.mej.0000209054.70634.1d

5. Barr LV, Imam S, Owen PJ: Skating on thin ice: a study of the injuries sustained at a temporary ice skating rink. Int Orthop. 2010, 34:743-746. 10.1007/s00264-010-0953-4

6. Brown MG: Ice rink injuries: a new epidemic in Northern Ireland . Ulster Med J. 1989, 58:69-71.

7. Williamson DM, Lowdon IMR: Ice-skating injuries. Injury. 1986, 17:205-207. 10.1016/0020-1383(86)90338-4

8. Matsumoto K, Sumi H, Sumi Y, Shimizu K: Wrist fractures from snowboarding . Clin J Sport Med. 2004, 14:64-71. 10.1097/00042752-200403000-00003

9. Radford PJ, Williamson DM, Lowdon IM: The risks of injury in public ice skating . Brit J Sports Med. 1988, 22:78-80. 10.1136/bjsm.22.2.78

10. Dubravčić-Šimunjak S, Kuipers H, Moran J, Šimunjak B, Pećina M: Injuries in synchronized skating . Int J Sports Med. 2006, 27:493-499. 10.1055/s-2005-865816

11. Kelsal NKR, Bowyer GW: Injuries sustained at a temporary ice-skating rink: prospective study of the 


\section{Cureus}

Winchester experience 2007-2008. Injury. 2009, 40:1276-1278. 10.1016/j.injury.2009.02.006 